\title{
World Health Organization fracture risk assessment tool in the assessment of fractures after falls in hospital
}

\author{
Shin-ichi Toyabe
}

\begin{abstract}
Background: Falls are very common accidents in a hospital. Various risk factors and risk assessment tools are used to predict falls. However, outcomes of falls such as bone fractures have not been considered in these risk assessment tools, and the performance of risk assessment tools in a Japanese hospital setting is not clear.

Methods: This was a retrospective single-institution study of 20,320 inpatients aged from 40 to 90 years who were admitted to a tertiary-care university hospital during the period from April 2006 to March 2009. Possible risk factors for falls and fractures including STRATIFY score and FRAX ${ }^{\mathrm{TM}}$ score and information on falls and their outcome were obtained from the hospital information system. The datasets were divided randomly into a development dataset and a test dataset. The chi-square test, logistic regression analysis and survival analysis were used to identify risk factors for falls and fractures after falls.

Results: Fallers accounted for $3.1 \%$ of the patients in the development dataset and $3.5 \%$ of the patients in the test dataset, and $2.6 \%$ and $2.9 \%$ of the fallers in those datasets suffered peripheral fractures. Sensitivity and specificity of the STRATIFY score to predict falls were not optimal. Most of the known risk factors for falls had no power to predict fractures after falls. Multiple logistic analysis and multivariate Cox's regression analysis with time-dependent covariates revealed that $F R A X^{\text {TM }}$ score was significantly associated with fractures after falls.

Conclusions: Risk assessment tools for falls are not appropriate for predicting fractures after falls. FRAX'M might be a useful tool for that purpose. The performance of STRATIFY to predict falls in a Japanese hospital setting was similar to that in previous studies.
\end{abstract}

\section{Background}

Falls are very common accidents in a hospital [1]. Falls in a hospital often cause severe injuries such as bone fractures, soft tissue injuries and hematomas. About 3-10\% of falls in hospitals result in physical injuries including fractures [2]. Risk of hip fracture has been shown to be eleven-times greater in hospital patients than in the general community [3]. These injuries may lead to additional healthcare costs, prolonged length of hospital stay and psychological distress for the patients. This situation might result in complaints and litigation from families of the patients [4].

\footnotetext{
* Correspondence: toyabe@med.niigata-u.ac.jp

${ }^{1}$ Niigata University Crisis Mangement Office, Niigata University Hospital, Asahimachi-dori 1-754, Chuoku, Niigata City 951-8520, Japan Full list of author information is available at the end of the article
}

A strategy that has been shown to be successful in preventing falls of inpatients is a target prevention strategy by selecting patients at high risk for falls [5-7]. Several clinical characteristics have been shown to be associated with increased incidence of falls in a hospital, and various risk assessment tools for falls have been developed [4,813]. In Japan, even the performance of popular risk assessment tools for inpatient falls has not been examined, making international comparison difficult $[1,12]$. A more important problem of these risk assessment tools is that these tools were developed to find patients at high risk for falls and not to predict patients who would suffer physical injuries after falls. In reality, more than $90 \%$ of inpatient falls do not result in physical injuries [2], but the costs attributable to falls are highly skewed to those that result in physical injuries. One of the most important rea- 
sons for preventing falls should be to prevent fractures and other severe injuries [5]. Risk assessment tools are needed to predict falls that are likely to be complicated with severe injuries such as fractures.

Measurement of bone mineral density (BMD) is the standard tool to assess susceptibility to fracture, but it is costly and impractical to measure BMD in all inpatients. Recently, fractures risk assessment tool $\left(\mathrm{FRAX}^{\mathrm{m}}\right.$ ) was developed by the World Health Organization [14-16]. FRAX $^{\text {mo }}$ has the advantage that it can be used without information on BMD and is adjusted for ethnic differences. The aims of this study were (i) to analyze the risk factors for fractures after falls among various patient characteristics including FRAX ${ }^{\mathrm{mw}}$ score and (ii) to examine the performance of the STRATFY tool (St. Thomas risk assessment tool in falling elderly) [17] in a Japanese hospital setting.

\section{Methods}

\section{Settings}

This study was conducted at Niigata University Hospital, an 810-bed academic teaching hospital in the city of Niigata. There are 23 clinical departments and the service area of the hospital as a tertiary care hospital covers all districts in Niigata Prefecture, which has a population of $2,400,000$. All patients who had been admitted to the hospital during the period from April 2006 to March 2009 and who were aged from 40 to 90 years at admission were studied. During that period, 20,973 patients were admitted to the hospital, but 653 patients were excluded from the study because of missing data. Finally, data were obtained for a total of 20,320 patients aged from 40 to 90 years (median, 65.0 years; 25th percentile, 56.0 years; 75 th percentile, 74.0 years). The patients included 9,738 females and 10,582 males, and 4,949 (24.4\%) of the patients required acute admission. The dataset was randomly divided into two datasets of the same sizes by a person blinded to our study. One dataset was used for receiver operating curve (ROC) analysis to determine cut-off values (development dataset) and the other was used for validation of the analysis (test dataset).

\section{Risk assessment tools for falls and fractures}

Various risk assessment tools for prediction of inpatient falls have been developed, but only the STRATIFY tool and the Morse Falls Scale [18] have been subjected to prospective validation in several cohorts with appropriate tests of predictive validity $[7,8]$. The STRATIFY tool showed high sensitivity and specificity in the original study, and its simplicity has facilitated its wide use in clinical practice [19]. We therefore used this tool in our study to assess patients' risk for falls. However, systematic review of the STRATIFY tool revealed that the tool may not be optimal for identifying individuals at high risk for falls and that population and setting affect performance of the tool [10]. The risk factors of fractures related to osteoporosis are age, prior fragility fracture, parental history of hip fracture, smoking, use of systemic corticosteroids, excess alcohol intake and rheumatoid arthritis [15]. By integrating these risk factors, WHO proposed the FRAX $^{\text {mi }}$ tool to compute ten-year probability of osteoporotic fracture. The FRAX ${ }^{\mathrm{m}}$ tool has the advantage that it can be used without information on BMD and is adjusted for ethnic differences. Actually, it is used to determine thresholds for therapeutic intervention in a Japanese setting [14]. We therefore used the tool in this study to assess the risk for fracture.

\section{Data collection}

Information on patients' background such as age, gender, body weight, height, history of bone fractures, smoking history, alcohol consumption, prescription of drugs, coexisting illness, admission day and discharge day was obtained from the hospital information system. Information on risk factors for falls was obtained from medical charts of the patients and fall assessment records completed by attending nurses at admission [8]. They included history of falls, gait instability, agitated confusion, urinary incontinence or frequency, visual impairment, lower limb weakness and prescription of 'culprit' drugs. The assessment was performed again when fall events occurred. Therefore, STRATIFY score [17] and FRAX $^{\text {ma }}$ score $[14,16]$ were calculated at admission and when the fall events occurred. STRATIFY score was calculated on the basis of the original method [17], and FRAX $^{\mathrm{m}}$ score was based on the ten-year probability of major osteoporotic fracture according to body mass index.

\section{Falls and fractures after falls}

The clinical outcome we studied was fallers with or without fractures rather than falls $[9,20]$. Data on fall events were obtained from online incident reports, records of $\mathrm{x}$ ray order entry and medical charts of the patients. The incident reports concerning fall events were documented by the attending nurse and other medical staff, and the reports contained data on time, location, injury sustained and potential causative factor for falls. Peripheral fractures verified by radiological findings were included, but vertebral fractures were excluded from the study [20].

\section{Statistical analysis}

Fall events and fracture after falls were analyzed by two different methods. The first method is the traditional chisquare test and multiple logistic analysis, which has been used for analysis of inpatient falls. For multiple logistic analysis, significant risk factors were selected by using the stepwise selection method and by the forced entery method. The second method is survival analysis in which 
time between admission and the event (falls or fractures after falls) during the hospital stay was considered as survival time. Discharge of the patient without fall events was considered as censoring. The Kaplan-Meier method was used for the analysis, and the logrank test was used to examine whether each risk factor was significantly associated with events. Multivariate Cox's proportional hazards regression model with time-dependent covariates was used to examine the risk factors that were most significantly associated with events among the various risk factors. Since values of several risk factors such as history of falls varied over time, these factors were included in the model by defining them as time-dependent covariates. Significant factors were selected by the stepwise selection method and by the forced entry method. A cut-off value to distinguish patients at risk from patients not at risk was determined on the basis of results of ROC analysis of data in the development dataset. The value corresponding to the nearest point of the ROC curve to the top lefthand corner was chosen as a cut-off value to distinguish patients at risk from patients not at risk [21]. Sensitivity, specificity and area under the ROC curve (AUC) were calculated. Distribution of continuous data was shown by medians (25-percentiles, 75-percentiles). All statistical analyses were performed using SPSS Statistics 17.0 (SPSS Japan Inc., Tokyo, Japan), and a p-value less than 0.05 was considered significant.

\section{Ethical consideration}

All data were analyzed anonymously. The Ethical Committee of Niigata University School of Medicine gave ethical approval.

Table 1: Results of univariate analysis of risk factors for falls.

\begin{tabular}{|c|c|c|c|c|c|}
\hline \multirow[t]{2}{*}{ Dataset } & \multirow[t]{2}{*}{ Items } & \multicolumn{2}{|c|}{ Number of patients } & \multicolumn{2}{|c|}{ Sig. } \\
\hline & & Fallers & Non fallers & Chi-square test & Logrank test \\
\hline \multirow{10}{*}{$\begin{array}{l}\text { Development dataset } \\
(\mathrm{n}=10,160)\end{array}$} & $\mathrm{n}$ & 308 & 9,852 & & \\
\hline & History of falls & 115 & 677 & $<0.001$ & $<0.001$ \\
\hline & Gait instability & 84 & 774 & $<0.001$ & $<0.001$ \\
\hline & Agitated confusion & 85 & 513 & $<0.001$ & $<0.001$ \\
\hline & $\begin{array}{l}\text { Urinary incontinence/ } \\
\text { frequency }\end{array}$ & 65 & 785 & $<0.001$ & $<0.001$ \\
\hline & Visual impairment & 69 & 1,807 & 0.083 & 0.154 \\
\hline & Lower limb weakness & 143 & 1,614 & $<0.001$ & $<0.001$ \\
\hline & $\begin{array}{l}\text { Prescription of 'culprit' } \\
\text { drugs }\end{array}$ & 79 & 1,158 & $<0.001$ & $<0.001$ \\
\hline & STRATIFY score $\geq 2$ & 190 & 2,055 & $<0.001$ & $<0.001$ \\
\hline & $\mathrm{LOS} \geq 14$ & 157 & 4,836 & 0.552 & - \\
\hline \multirow{10}{*}{$\begin{array}{l}\text { Test dataset } \\
(\mathrm{n}=10,160)\end{array}$} & $\mathrm{n}$ & 345 & 9,815 & & \\
\hline & History of falls & 132 & 681 & $<0.001$ & $<0.001$ \\
\hline & Gait instability & 100 & 735 & $<0.001$ & $<0.001$ \\
\hline & Agitated confusion & 81 & 519 & $<0.001$ & $<0.001$ \\
\hline & $\begin{array}{l}\text { Urinary incontinence/ } \\
\text { frequency }\end{array}$ & 76 & 801 & $<0.001$ & $<0.001$ \\
\hline & Visual impairment & 74 & 1,811 & 0.181 & 0.158 \\
\hline & Lower limb weakness & 157 & 1,555 & $<0.001$ & $<0.001$ \\
\hline & $\begin{array}{l}\text { Prescription of 'culprit' } \\
\text { drugs }\end{array}$ & 83 & 1,165 & $<0.001$ & 0.002 \\
\hline & STRATIFY score $\geq 2$ & 221 & 2,039 & $<0.001$ & $<0.001$ \\
\hline & $\operatorname{LOS} \geq 14$ & 193 & 4,917 & 0.038 & - \\
\hline
\end{tabular}


Table 2: Sensitivity and specificity of the STRATIFY score and the FRAX ${ }^{\mathrm{Tm}}$ score.

A

\begin{tabular}{|c|c|c|c|c|c|}
\hline \multirow[t]{2}{*}{ Items } & \multirow[t]{2}{*}{ Events } & \multirow[t]{2}{*}{ Datasets } & \multirow[t]{2}{*}{ AUC } & \multicolumn{2}{|c|}{$95 \% \mathrm{Cl}$} \\
\hline & & & & lower & upper \\
\hline \multirow[t]{4}{*}{ STRATIFY } & Falls & Development dataset & 0.749 & 0.719 & 0.779 \\
\hline & & Test dataset & 0.765 & 0.736 & 0.794 \\
\hline & Fracture after falls & Development dataset & 0.717 & 0.549 & 0.885 \\
\hline & & Test dataset & 0.636 & 0.464 & 0.808 \\
\hline \multirow[t]{4}{*}{ FRAX } & Falls & Development dataset & 0.606 & 0.574 & 0.637 \\
\hline & & Test dataset & 0.589 & 0.557 & 0.620 \\
\hline & Fracture after falls & Development dataset & 0.749 & 0.580 & 0.917 \\
\hline & & Test dataset & 0.727 & 0.552 & 0.901 \\
\hline
\end{tabular}

B

\begin{tabular}{|c|c|c|c|c|c|c|c|c|}
\hline \multirow[t]{2}{*}{ Items } & \multirow[t]{2}{*}{ Events } & \multirow[t]{2}{*}{ Datasets } & \multirow[t]{2}{*}{ Sensitivity } & \multicolumn{2}{|c|}{$95 \% \mathrm{Cl}$} & \multirow[t]{2}{*}{ Specificity } & \multicolumn{2}{|c|}{$95 \% \mathrm{Cl}$} \\
\hline & & & & lower & upper & & lower & upper \\
\hline \multirow[t]{4}{*}{ STRATIFY } & Falls & Development dataset & 0.648 & 0.592 & 0.701 & 0.749 & 0.740 & 0.759 \\
\hline & & Test dataset & 0.678 & 0.625 & 0.726 & 0.749 & 0.739 & 0.758 \\
\hline & Fracture after falls & Development dataset & 0.625 & 0.306 & 0.863 & 0.736 & 0.726 & 0.745 \\
\hline & & Test dataset & 0.400 & 0.168 & 0.687 & 0.732 & 0.723 & 0.742 \\
\hline \multirow[t]{4}{*}{ FRAX } & Falls & Development dataset & 0.481 & 0.425 & 0.536 & 0.663 & 0.654 & 0.672 \\
\hline & & Test dataset & 0.496 & 0.443 & 0.548 & 0.666 & 0.657 & 0.675 \\
\hline & Fracture after falls & Development dataset & 0.750 & 0.409 & 0.929 & 0.659 & 0.620 & 0.668 \\
\hline & & Test dataset & 0.700 & 0.397 & 0.892 & 0.661 & 0.652 & 0.670 \\
\hline
\end{tabular}

AUC (A), sensitivity and specificity (B) of the STRATIFY score and the FRAX ${ }^{\mathrm{TM}}$ score to detect falls and fracture after falls were calculated. Cutoff values for the STRATIFY score and the FRAX ${ }^{\mathrm{TM}}$ score were set at 2 and 10 , respectively.

\section{Results}

\section{Falls and fractures after falls}

The numbers of patients who experienced more than one fall during admission were $308(3.1 \%)$ in the development dataset and $345(3.4 \%)$ in the test dataset. Eight $(2.6 \%)$ of the fallers in the development dataset and $10(2.9 \%)$ of the fallers in the test dataset suffered peripheral fractures after falls. The ages of the patients who suffered fractures after falls were $78.0(64.0,83.0)$ years for the development dataset and $75.0(64.5,76.5)$ years for the test dataset. All but one of the patients who suffered peripheral fractures broke bones during the first fall.

\section{Risk factors for falls}

Univariate analyses (chi-square test and logrank test) revealed that various known risk factors including 
Table 3: Results of multivariate analysis of risk factors for falls.

\begin{tabular}{|c|c|c|c|c|c|c|}
\hline \multicolumn{7}{|l|}{ A } \\
\hline Datasets & Items & $\begin{array}{c}\text { Estimated } \\
\text { coefficient }(\boldsymbol{\beta})\end{array}$ & $\begin{array}{c}\text { Standard error } \\
\text { for } \beta\end{array}$ & Sig. & OR & $95 \% \mathrm{Cl}$ for $\mathrm{OR}$ \\
\hline \multirow{6}{*}{$\begin{array}{l}\text { Development } \\
\text { dataset }\end{array}$} & History of falls & 0.919 & 0.169 & $<0.001$ & 2.507 & $1.801-3.489$ \\
\hline & Gait instability & 0.451 & 0.153 & 0.003 & 1.571 & $1.164-2.119$ \\
\hline & Agitated confusion & 0.698 & 0.180 & $<0.001$ & 2.009 & $1.412-2.859$ \\
\hline & $\begin{array}{l}\text { Lower limb } \\
\text { weakness }\end{array}$ & 0.444 & 0.143 & 0.002 & 1.559 & $1.178-2.063$ \\
\hline & STRATIFY score & 0.335 & 0.072 & $<0.001$ & 1.397 & $1.214-1.609$ \\
\hline & Constant & -4.341 & 0.110 & $<0.001$ & 0.013 & \\
\hline \multirow[t]{5}{*}{ Test dataset } & History of falls & 0.759 & 0.155 & $<0.001$ & 2.137 & $1.577-2.897$ \\
\hline & Gait instability & 0.526 & 0.145 & $<0.001$ & 1.692 & $1.275-2.247$ \\
\hline & $\begin{array}{l}\text { Lower limb } \\
\text { weakness }\end{array}$ & 0.332 & 0.137 & 0.015 & 1.394 & $1.066-1.824$ \\
\hline & STRATIFY score & 0.550 & 0.058 & $<0.001$ & 1.734 & $1.547-1.944$ \\
\hline & Constant & -4.420 & 0.109 & $<0.001$ & 0.012 & \\
\hline
\end{tabular}

B

\begin{tabular}{|c|c|c|c|c|c|c|}
\hline Datasets & Items & $\begin{array}{c}\text { Estimated } \\
\text { coefficient }(\boldsymbol{\beta})\end{array}$ & $\begin{array}{c}\text { Standard error } \\
\text { for } \beta\end{array}$ & Sig. & HR & 95\% Cl for HR \\
\hline \multirow{5}{*}{$\begin{array}{l}\text { Development } \\
\text { dataset }\end{array}$} & History of falls & 0.945 & 0.158 & $<0.001$ & 2.572 & $1.888-3.505$ \\
\hline & Gait instability & 0.470 & 0.139 & 0.001 & 1.599 & $1.217-2.102$ \\
\hline & Agitated confusion & 0.475 & 0.167 & 0.005 & 1.609 & $1.158-2.233$ \\
\hline & $\begin{array}{l}\text { Lower limb } \\
\text { weakness }\end{array}$ & 0.273 & 0.136 & 0.045 & 1.313 & $1.006-1.714$ \\
\hline & STRATIFY score & 0.265 & 0.069 & $<0.001$ & 1.303 & $1.139-1.492$ \\
\hline \multirow[t]{2}{*}{ Test dataset } & History of falls & 0.677 & 0.147 & $<0.001$ & 1.968 & $1.475-2.627$ \\
\hline & STRATIFY score & 0.469 & 0.052 & $<0.001$ & 1.598 & $1.442-1.770$ \\
\hline
\end{tabular}

Risk factors shown in Table 1 were analyzed by multiple logistic regression analysis (A) and multivariate Cox's regression analysis in development and test datasets (B). Significant factors were selected by using the stepwise selection method. Cl, confidence interval; LOS, length of hospital stay; OR, odds ratio; HR, hazards ratio.

dichotomized STRATIFY score were significantly associated with fallers (Table 1). The cut-off value of the STRATIFY score to predict falls was determined to be a value of 2 based on results of ROC analysis of data in the development dataset. Proportions of high-risk patients based on the cut-off value of STRATIFY score were 26.5\% in the development dataset and $26.8 \%$ in the test dataset. Sensitivity and specificity of the cut-off value to predict falls were 0.648 and 0.749 in the development dataset and 0.678 and 0.749 in the test dataset, respectively (Table 2). LOS was dichotomized at 14 days, which was the median value for all patients. Only the factor 'visual impairment' was not significant. When the risk factors as well as STRATIFY score were entered simultaneously into the multiple logisitc model, factors shown in Table A3A were significantly associated. On the other hand, multivariate 


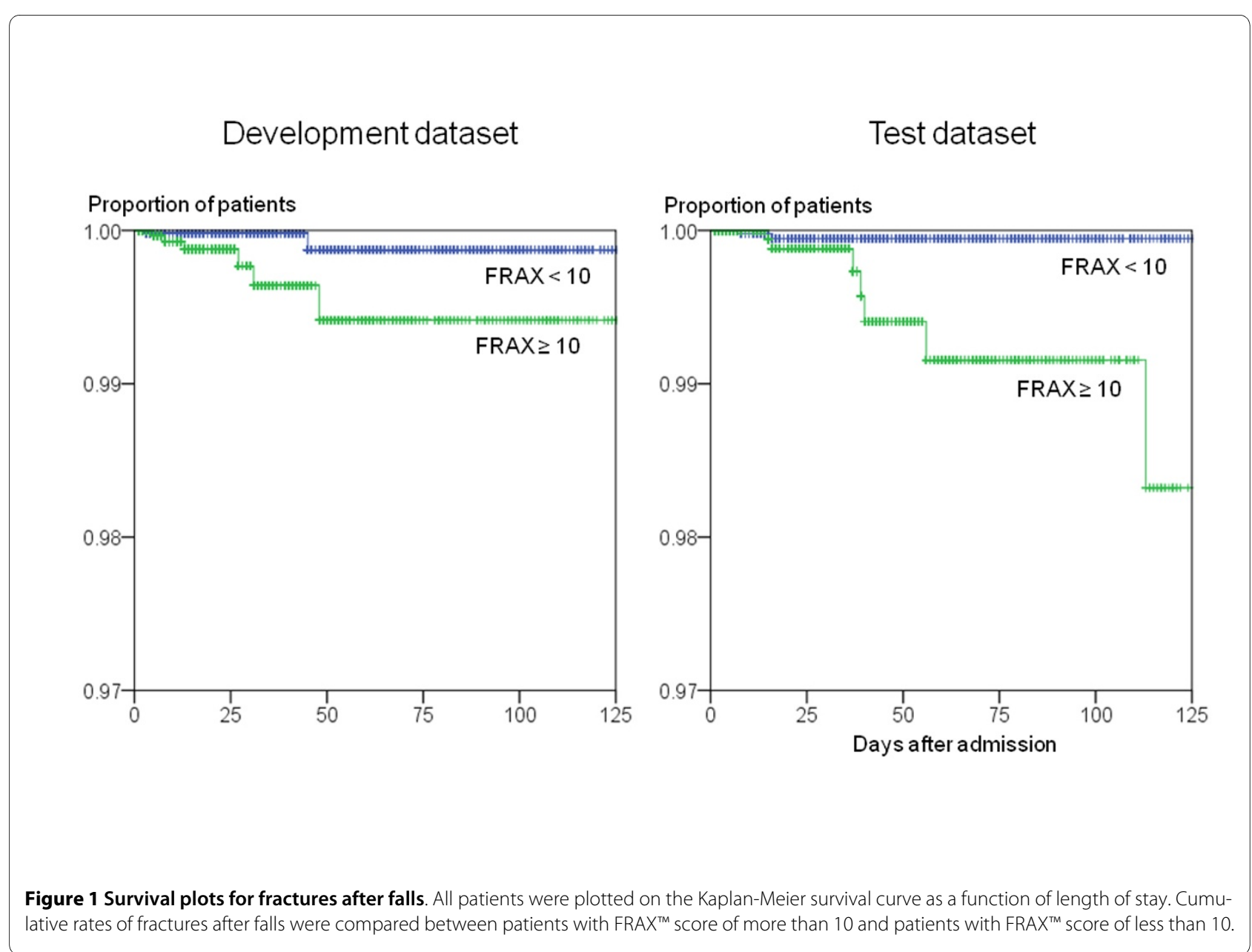

Cox's regression analysis showed that the factors in Table $\mathrm{B} 3 \mathrm{~B}$ were significantly associated with falls. In both datasets, the factor 'history of falls', factor 'gait instability' and STRATIFY score were significantly associated with falls in both analyses.

\section{Risk factors for fractures after falls}

The chi-square test revealed that the factor 'lower limb weakness' and the FRAX ${ }^{\mathrm{m}}$ score were significantly associated with fracture after falls in both datasets (Table 4). In addition, dichotomized STRATIFY score was a significant factor in the development dataset and dichotomized LOS was a significant factor in the test dataset. The cutoff value of the FRAX ${ }^{\mathrm{ma}}$ score to predict fracture after falls was determined to be as a value of 10 based on results of ROC analysis of data in the development dataset. Proportions of high-risk patients based on the cut-off value of FRAX $^{\mathrm{Tm}}$ score were $34.1 \%$ in the development dataset and $33.9 \%$ in the test dataset. Sensitivity and specificity of the cut-off value were 0.750 and 0.659 in the development dataset and 0.700 and 0.661 in the test dataset, respectively (Table B2B). On the other hand, the logrank test revealed that only dichotomized FRAX ${ }^{\mathrm{mm}}$ score was signif- icantly associated with fractures after falls both in the development dataset and the test dataset (Table 4, Figure 1 ). When the risk factors shown in Table 4 were entered into the multiple logisitc regression model, only FRAX ${ }^{\mathrm{Tm}}$ score was selected as a factor significantly associated with fractures after falls by the stepwise selection method both in the development dataset and the test dataset (Table A5A). Similarly, multivariate Cox's regression analysis showed that only FRAX ${ }^{\mathrm{T}}$ score was a significant factor (Table B5B). Next, we analyzed how the combination of STRATIFY and FRAX ${ }^{\mathrm{sm}}$ tools would work for prediction of fracture after falls. Both scores were forcibly entered into the multiple logisitc model (Table C5C) and multivariate Cox's regression model (Table D5D), but only FRAX $^{\mathrm{TM}}$ score was significantly associated with fracture after falls in Cox's regression analysis.

\section{Risk factors in aged patients}

The performance of the two risk tools in a much more selected population was evaluated. We performed multiple logisitc analysis and multivariate Cox's regression analysis by entering the risk factors as well as the two risk scores simultaneously into the models for patients more 
Table 4: Results of univariate analysis of risk factors for fractures after falls.

\begin{tabular}{|c|c|c|c|c|c|}
\hline \multirow[t]{2}{*}{ Dataset } & \multirow[t]{2}{*}{ Items } & \multicolumn{2}{|c|}{ Number of patients } & \multicolumn{2}{|c|}{ Sig. } \\
\hline & & $\begin{array}{c}\text { Fallers with } \\
\text { fracture after } \\
\text { falls }\end{array}$ & $\begin{array}{c}\text { Non fallers and } \\
\text { fallers without } \\
\text { fractures after } \\
\text { falls }\end{array}$ & Chi-square test & Logrank test \\
\hline \multirow{11}{*}{$\begin{array}{l}\text { Development } \\
\text { dataset } \\
(n=10,160)\end{array}$} & $\mathrm{n}$ & 8 & 10,152 & & \\
\hline & History of falls & 2 & 790 & 0.248 & 0.233 \\
\hline & Gait instability & 0 & 858 & 0.823 & 0.292 \\
\hline & Agitated confusion & 2 & 596 & 0.122 & 0.162 \\
\hline & $\begin{array}{l}\text { Urinary } \\
\text { incontinence/ } \\
\text { frequency }\end{array}$ & 0 & 850 & 0.829 & 0.306 \\
\hline & Visual impairment & 3 & 1,873 & 0.351 & 0.200 \\
\hline & $\begin{array}{l}\text { Lower limb } \\
\text { weakness }\end{array}$ & 4 & 1,753 & 0.048 & 0.110 \\
\hline & $\begin{array}{l}\text { Prescription of } \\
\text { 'culprit' drugs }\end{array}$ & 3 & 1,234 & 0.099 & 0.140 \\
\hline & STRATIFY score $\geq 2$ & 5 & 2,240 & 0.020 & 0.071 \\
\hline & FRAX score $\geq 10.0$ & 6 & 3,561 & 0.046 & 0.019 \\
\hline & $\mathrm{LOS} \geq 14$ & 4 & 4,989 & 1.000 & - \\
\hline \multirow{11}{*}{$\begin{array}{l}\text { Test dataset } \\
(\mathrm{n}=10,160)\end{array}$} & $\mathrm{n}$ & 10 & 10,150 & & \\
\hline & History of falls & 2 & 811 & 0.415 & 0.599 \\
\hline & Gait instability & 1 & 835 & 1.000 & 0.777 \\
\hline & Agitated confusion & 1 & 600 & 1.000 & 0.915 \\
\hline & $\begin{array}{l}\text { Urinary } \\
\text { incontinence/ } \\
\text { frequency }\end{array}$ & 2 & 877 & 0.475 & 0.402 \\
\hline & Visual impairment & 4 & 1,885 & 0.182 & 0.055 \\
\hline & $\begin{array}{l}\text { Lower limb } \\
\text { weakness }\end{array}$ & 5 & 1,712 & 0.018 & 0.143 \\
\hline & $\begin{array}{l}\text { Prescription of } \\
\text { 'culprit' drugs }\end{array}$ & 2 & 1,248 & 0.795 & 0.920 \\
\hline & STRATIFY score $\geq 2$ & 4 & 2,260 & 0.334 & 0.819 \\
\hline & FRAX score $\geq 10.0$ & 7 & 3,518 & 0.044 & 0.025 \\
\hline & $\operatorname{LOS} \geq 14$ & 9 & 5,110 & 0.028 & - \\
\hline
\end{tabular}

Various risk factors for falls, STRATIFY score and FRAX ${ }^{\mathrm{TM}}$ score were evaluated to determine whether they are associated with fractures after falls by using the chi-square test and logrank test. LOS, length of hospital stay. FRAX'M score was dichotomized at 10.

than 65 years old, who were at higher risk for both falls and fractures. The results were almost the same as the results of analysis for all subjects (Table 6). The factor 'history of falls', the factor 'gait instability' and STRATIFY score were significantly associated with falls both in multiple logistic regression analysis (Table A6A) and multi- variate Cox's regression analysis (Table B6B). FRAX ${ }^{\mathrm{ms}}$ was significantly associated with fracture after falls in the development dataset analyzed by multivariate Cox's regression analysis and in the test dataset analyzed by both methods. 
Table 5: Results of multivariate analysis of risk factors for fractures after falls.

\begin{tabular}{|c|c|c|c|c|c|c|}
\hline Datasets & Items & $\begin{array}{c}\text { Estimated } \\
\text { coefficient }(\boldsymbol{\beta})\end{array}$ & $\begin{array}{l}\text { Standard } \\
\text { error for } \beta\end{array}$ & Sig. & OR & $95 \% \mathrm{Cl}$ for $\mathrm{OR}$ \\
\hline \multirow{2}{*}{$\begin{array}{l}\text { Developme } \\
\text { nt dataset }\end{array}$} & FRAX score & 0.069 & 0.026 & 0.008 & 1.072 & $1.018-1.128$ \\
\hline & Constant & -7.865 & 0.572 & $<0.001$ & 0.000 & \\
\hline \multirow[t]{2}{*}{ Test dataset } & FRAX score & 0.076 & 0.024 & 0.001 & 1.079 & $1.030-1.130$ \\
\hline & Constant & -7.726 & 0.524 & $<0.001$ & 0.000 & \\
\hline
\end{tabular}

B

\begin{tabular}{llcccrr}
\hline Datasets & Items & $\begin{array}{c}\text { Estimated } \\
\text { coefficient }(\boldsymbol{\beta})\end{array}$ & $\begin{array}{c}\text { Standard } \\
\text { error for } \boldsymbol{\beta}\end{array}$ & Sig. & HR & $\mathbf{9 5 \% ~ C l ~ f o r ~ H R ~}$ \\
\hline $\begin{array}{l}\text { Developme } \\
\text { nt dataset }\end{array}$ & FRAX score & 0.063 & 0.025 & 0.012 & 1.065 & $1.014-1.119$ \\
\hline Test dataset & FRAX score & 0.065 & 0.022 & 0.003 & 1.067 & $1.022-1.114$ \\
\hline
\end{tabular}

\section{C}

\begin{tabular}{|c|c|c|c|c|c|c|}
\hline Datasets & Items & $\begin{array}{c}\text { Estimated } \\
\text { coefficient }(\beta)\end{array}$ & $\begin{array}{l}\text { Standard } \\
\text { error for } \beta\end{array}$ & Sig. & OR & $95 \% \mathrm{Cl}$ for OR \\
\hline \multirow[t]{3}{*}{$\begin{array}{l}\text { Developme } \\
\text { nt dataset }\end{array}$} & $\begin{array}{l}\text { STRATIFY } \\
\text { score }\end{array}$ & 0.443 & 0.256 & 0.083 & 1.557 & $0.943-2.569$ \\
\hline & FRAX score & 0.060 & 0.028 & 0.034 & 1.062 & $1.004-1.122$ \\
\hline & Constant & -8.358 & 0.697 & $<0.001$ & 0.000 & \\
\hline \multirow[t]{3}{*}{ Test dataset } & $\begin{array}{l}\text { STRATIFY } \\
\text { score }\end{array}$ & 0.289 & 0.241 & 0.231 & 1.335 & $0.832-2.141$ \\
\hline & FRAX score & 0.070 & 0.025 & 0.004 & 1.072 & $1.022-1.125$ \\
\hline & Constant & -8.020 & 0.603 & $<0.001$ & 0.000 & \\
\hline
\end{tabular}

D

\begin{tabular}{llcccrr}
\hline Datasets & Items & $\begin{array}{c}\text { Estimated } \\
\text { coefficient }(\boldsymbol{\beta})\end{array}$ & $\begin{array}{c}\text { Standard } \\
\text { error for } \boldsymbol{\beta}\end{array}$ & Sig. & HR & $\mathbf{9 5 \% ~ C I ~ f o r ~ H R ~}$ \\
\hline $\begin{array}{l}\text { Developme } \\
\text { nt dataset }\end{array}$ & $\begin{array}{l}\text { STRATIFY } \\
\text { score } \\
\text { FRAX score }\end{array}$ & 0.330 & 0.257 & 0.200 & 1.391 & $0.840-2.302$ \\
\hline Test dataset & $\begin{array}{l}\text { STRATIFY } \\
\text { Score }\end{array}$ & 0.056 & 0.027 & 0.035 & 1.058 & $1.004-1.115$ \\
& FRAX score & 0.064 & 0.240 & 0.523 & 1.165 & $0.729-1.864$ \\
\end{tabular}

Various risk factors for falls, STRATIFY score and FRAX ${ }^{\mathrm{TM}}$ score were evaluated in development and test datasets to determine whether they are associated with fracture after falls by using multiple logistic regression analysis (A) and multivariate Cox's regression analysis (B). Significant factors were selected by using the stepwise selection method. In Tables C and D, both STRATIFY score and FRAX ${ }^{\mathrm{TM}}$ score were forcibly entered into the logistic model (C) and Cox's regression model (D). Cl, confident interval; LOS, length of hospital stay; OR, odds ratio; $H R$, hazards ratio. 
Table 6: Risk factors for falls and for fractures after falls in patients over $\mathbf{6 5}$ years old.

\begin{tabular}{|c|c|c|c|c|c|c|}
\hline Datasets & Items & $\begin{array}{c}\text { Estimated } \\
\text { coefficient }(\beta)\end{array}$ & $\begin{array}{l}\text { Standard } \\
\text { error for } \beta\end{array}$ & Sig. & OR & $95 \% \mathrm{Cl}$ for OR \\
\hline \multirow{6}{*}{$\begin{array}{l}\text { Development } \\
\text { dataset }\end{array}$} & History of falls & 0.971 & 0.199 & $<0.001$ & 2.640 & $1.788-3.898$ \\
\hline & Gait instability & 0.527 & 0.182 & 0.004 & 1.694 & $1.185-2.422$ \\
\hline & $\begin{array}{l}\text { Agitated } \\
\text { confusion }\end{array}$ & 0.731 & 0.212 & 0.001 & 2.078 & $1.373-3.145$ \\
\hline & $\begin{array}{l}\text { Lower limb } \\
\text { weakness }\end{array}$ & 0.397 & 0.171 & 0.020 & 1.487 & $1.063-2.079$ \\
\hline & $\begin{array}{l}\text { STRATIFY } \\
\text { score }\end{array}$ & 0.275 & 0.086 & 0.001 & 1.316 & $1.112-1.558$ \\
\hline & Constant & -4.205 & 0.140 & $<0.001$ & 0.015 & \\
\hline \multirow[t]{5}{*}{ Test dataset } & History of falls & 0.727 & 0.183 & $<0.001$ & 2.069 & $1.447-2.959$ \\
\hline & Gait instability & 0.574 & 0.172 & 0.001 & 1.775 & $1.268-2.484$ \\
\hline & $\begin{array}{l}\text { Lower limb } \\
\text { weakness }\end{array}$ & 0.346 & 0.160 & 0.031 & 1.413 & $1.033-1.933$ \\
\hline & $\begin{array}{l}\text { STRATIFY } \\
\text { score }\end{array}$ & 0.459 & 0.069 & $<0.001$ & 1.583 & $1.382-1.814$ \\
\hline & Constant & -4.142 & 0.132 & $<0.001$ & 0.016 & \\
\hline
\end{tabular}

B

\begin{tabular}{|c|c|c|c|c|c|c|}
\hline Datasets & Items & $\begin{array}{c}\text { Estimated } \\
\text { coefficient }(\beta)\end{array}$ & $\begin{array}{l}\text { Standard } \\
\text { error for } \beta\end{array}$ & Sig. & HR & $95 \% \mathrm{Cl}$ for $\mathrm{HR}$ \\
\hline \multirow{4}{*}{$\begin{array}{l}\text { Development } \\
\text { dataset }\end{array}$} & History of falls & 0.977 & 0.188 & $<0.001$ & 2.655 & $1.838-3.836$ \\
\hline & Gait instability & 0.576 & 0.163 & $<0.001$ & 1.780 & $1.292-2.451$ \\
\hline & $\begin{array}{l}\text { Agitated } \\
\text { confusion }\end{array}$ & 0.534 & 0.198 & 0.007 & 1.705 & $1.156-2.514$ \\
\hline & $\begin{array}{l}\text { STRATIFY } \\
\text { score }\end{array}$ & 0.239 & 0.080 & 0.003 & 1.270 & $1.085-1.486$ \\
\hline \multirow[t]{3}{*}{ Test dataset } & History of falls & 0.594 & 0.172 & 0.001 & 1.812 & $1.294-2.536$ \\
\hline & Gait instability & 0.649 & 0.151 & $<0.001$ & 1.913 & $1.424-2.571$ \\
\hline & $\begin{array}{l}\text { STRATIFY } \\
\text { score }\end{array}$ & 0.403 & 0.062 & $<0.001$ & 1.497 & $1.325-1.690$ \\
\hline
\end{tabular}


Table 6: Risk factors for falls and for fractures after falls in patients over $\mathbf{6 5}$ years old. (Continued)

\begin{tabular}{|c|c|c|c|c|c|c|}
\hline Datasets & Items & $\begin{array}{c}\text { Estimated } \\
\text { coefficient }(\boldsymbol{\beta})\end{array}$ & $\begin{array}{l}\text { Standard } \\
\text { error for } \beta\end{array}$ & Sig. & OR & $95 \% \mathrm{Cl}$ for $\mathrm{OR}$ \\
\hline \multirow[t]{2}{*}{$\begin{array}{l}\text { Development } \\
\text { dataset }\end{array}$} & $\begin{array}{l}\text { Lower limb } \\
\text { weakness }\end{array}$ & 1.728 & 0.867 & 0.046 & 5.631 & $1.030-30.780$ \\
\hline & Constant & -7.496 & 0.707 & $<0.001$ & 0.001 & \\
\hline \multirow[t]{2}{*}{ Test dataset } & FRAX score & 0.069 & 0.028 & 0.012 & 1.072 & $1.015-1.131$ \\
\hline & Constant & -7.528 & 0.665 & $<0.001$ & 0.001 & \\
\hline
\end{tabular}

\begin{tabular}{|c|c|c|c|c|c|c|}
\hline \multicolumn{7}{|l|}{ D } \\
\hline Datasets & Items & $\begin{array}{c}\text { Estimated } \\
\text { coefficient }(\boldsymbol{\beta})\end{array}$ & $\begin{array}{l}\text { Standard } \\
\text { error for } \beta\end{array}$ & Sig. & HR & $95 \% \mathrm{Cl}$ for $\mathrm{HR}$ \\
\hline $\begin{array}{l}\text { Development } \\
\text { dataset }\end{array}$ & FRAX score & 0.060 & 0.031 & 0.050 & 1.062 & $1.000-1.128$ \\
\hline Test dataset & FRAX score & 0.061 & 0.027 & 0.023 & 1.063 & $1.008-1.120$ \\
\hline
\end{tabular}

\section{Discussion}

In this study, we analyzed the risk factors for falls resulting in fractures, focusing on FRAX ${ }^{\mathrm{Tm}}$ fracture risk assessment tool. Most of the risk factors for falls had no power to predict fracture after falls, but a high FRAX ${ }^{\mathrm{min}}$ score was closely associated with fractures. This result was confirmed not only by conventional multiple logisitc analysis but also by survival analysis referring to the fracture after a fall as event and the time between admission and the event as survival time. By using the risk assessment tools for fractures, we could identify and target fallers that were at high risk for fractures more efficiently.

Our results suggest that a strategy to prevent fractures after falls might require programs for patients with bone fragilities apart from a program to prevent falls. The majority of patients who fell did not injure themselves and only $2.6 \%-2.9 \%$ of patients who fell incurred a peripheral fracture. The risk assessment tools should be used for prediction of physical injuries resulting from falls, not for prediction of falls themselves. However, the existing risk assessment tools have poor performance in predicting not only fractures after falls but also falls themselves [10]. Several reports suggested that the risk assessment tools for falls have the same poor perfor- mance as clinical judgment of nurses [22-25]. The use of risk assessment tools for falls might have no clinical benefit and waste scarce nursing resources [23]. Hospitals should shift their emphasis from simply targeting highrisk patients for falls to identifying high-risk patients for fractures after falls and employing programs to prevent fractures. A targeted intervention for high-risk patients such as the use of a hip protector $[26,27]$ might be beneficial even though the compliance with a hip protector remains to be improved [28]. Our results suggest that a FRAX $^{\mathrm{mm}}$ score of more than 10 is useful for identifying the high-risk patients in terms of sensitivity. This cut-off point was consistent with the recommended threshold for therapeutic intervention for osteoporotic fracture in the Japanese population [14]. However, positive predictive value of FRAX ${ }^{\mathrm{mi}}$ score to predict fracture after falls was 0.003 in both datasets. The low positive predictive value was problematic when FRAX ${ }^{\mathrm{w}}$ score was used as a means of screening [29]. More restrictive selection of patients at high risk for fractures is necessary.

Our study is the first study in which the performance of STRATIFY tools was examined in a Japanese setting, but it was found that the performance of the STRATIFY risk assessment tool is not optimal in a Japanese acute-care 
hospital setting. This tool was originally developed and validated in the United Kingdom to predict falls occurring in a hospital, and sensitivity and specificity were both in excess $80 \%$ in the original study [17]. However, systemic review of this tool has shown that this tool has poorer predictive accuracy than the results of the original study and that population and setting affect the performance of this tool [10]. Our results showed that the performance of the STRATIFY tool was not necessarily satisfactory in a Japanese hospital setting but was similar to that in previous studies [30]. Since a weighted risk score based on the STRATIFY tool could improve the performance of the tool [9], modification of the tool might be needed for a Japanese setting.

There are several limitations of this study. First, we limited the study subjects to patients aged from 40 to 90 years. This was because the FRAX ${ }^{\mathrm{mo}}$ scoring system targets that age group. Second, no validation study using a prospective cohort was performed in this study. A prospective study is needed to validate the usefulness of the assessment tool for predicting fractures after falls and to generalize the findings of our study. Third, sensitivity and specificity of the STRATIFY tool for falls, which were calculated by the standard approach, might be incorrect because falls might be recurrent and time-dependent [31]. Finally and most importantly, the sample size of our study was small in terms of number of fractures to construct proper statistical models. Further investigation using larger sample sizes is needed to determine whether fracture risk assessment is useful for predicting fractures after inpatient falls.

\section{Conclusions}

Risk assessment tools for falls are not appropriate for predicting fractures after falls. FRAX ${ }^{\text {su }}$ might be a useful tool for that purpose. The performance of STRATIFY to predict falls in a Japanese hospital setting was similar to that in previous studies.

\section{Competing interests}

The author declares that they have no competing interests.

\section{Authors' contributions}

ST is solely responsible for this manuscript.

\section{Acknowledgements}

Part of this work was supported by KAKENHI (Grant-in-Aid for Scientific Research (B), No.21390159). KAKENHI is a project of the Japan Society for the Promotion of Science (JSPS).

\section{Author Details}

Niigata University Crisis Mangement Office, Niigata University Hospital, Asahimachi-dori 1-754, Chuoku, Niigata City 951-8520, Japan

Received: 13 July 2009 Accepted: 27 April 2010

Published: 27 April 2010
References

1. Nakai A, Akeda M, Kawabata I: Incidence and risk factors for inpatient falls in an academic acute-care hospital. J Nippon Med Sch 2006, 73(5):265-270

2. Fischer ID, Krauss MJ, Dunagan WC, Birge S, Hitcho E, Johnson S, Costantinou E, Fraser VJ: Patterns and predictors of inpatient falls and fall-related injuries in a large academic hospital. Infect Control Hosp Epidemiol 2005, 26(10):822-827.

3. Uden G, Nilsson B: Hip fracture frequent in hospital. Acta Orthop Scand 1986, 57(5):428-430

4. Oliver D, Killick S, Even T, Willmott M: Do falls and falls-injuries in hospital indicate negligent care -- and how big is the risk? A retrospective analysis of the NHS Litigation Authority Database of clinical negligence claims, resulting from falls in hospitals in England 1995 to 2006. Qual Saf Health Care 2008, 17(6):431-436.

5. Gates S, Fisher JD, Cooke MW, Carter YH, Lamb SE: Multifactoria assessment and targeted intervention for preventing falls and injuries among older people in community and emergency care settings: systematic review and meta-analysis. BMJ 2008, 336(7636):130-133.

6. Rubenstein LZ: Falls in older people: epidemiology, risk factors and strategies for prevention. Age Ageing 2006, 35(Suppl 2):ii37-ii41.

7. Haines TP, Hill K, Walsh W, Osborne R: Design-related bias in hospital fall risk screening tool predictive accuracy evaluations: systematic review and meta-analysis. J Gerontol A Biol Sci Med Sci 2007, 62(6):664-672.

8. Oliver D, Daly F, Martin FC, McMurdo ME: Risk factors and risk assessment tools for falls in hospital in-patients: a systematic review. Age Ageing 2004, 33(2):122-130.

9. Papaioannou A, Parkinson W, Cook R, Ferko N, Coker E, Adachi JD: Prediction of falls using a risk assessment tool in the acute care setting. BMC Med 2004, 2:1.

10. Oliver D, Papaioannou A, Giangregorio L, Thabane L, Reizgys K, Foster G: A systematic review and meta-analysis of studies using the STRATIFY tool for prediction of falls in hospital patients: how well does it work? Age Ageing 2008, 37(6):621-627.

11. Kim EA, Mordiffi SZ, Bee WH, Devi K, Evans D: Evaluation of three fall-risk assessment tools in an acute care setting. J Adv Nurs 2007, 60(4):427-435

12. Izumi K, Makimoto K, Kato M, Hiramatsu T: Prospective study of fall risk assessment among institutionalized elderly in Japan. Nurs Health Sci 2002, 4(4):141-147.

13. Heinze C, Dassen T, Halfens R, Lohrmann C: Screening the risk of falls: a general or a specific instrument? J Clin Nurs 2009, 18(3):350-356.

14. Fujiwara S, Nakamura T, Orimo H, Hosoi T, Gorai I, Oden A, Johansson H, Kanis JA: Development and application of a Japanese model of the WHO fracture risk assessment tool (FRAX). Osteoporos Int 2008, 19(4):429-435.

15. Kanis JA, Borgstrom F, De Laet $C$, Johansson $H_{\text {, Johnell } O}$, Jonsson B, Oden A, Zethraeus N, Pfleger B, Khaltaev N: Assessment of fracture risk. Osteoporos Int 2005, 16(6):581-589.

16. FRAX, WHO fracture risk assessment tool [http://www.shef.ac.uk/FRAX/ index.htm]

17. Oliver D, Britton M, Seed P, Martin FC, Hopper AH: Development and evaluation of evidence based risk assessment tool (STRATIFY) to predict which elderly inpatients will fall: case-control and cohort studies. BMJ 1997, 315(7115):1049-1053.

18. Morse JM: Preventing Patient Falls London: Sage Publications; 1995.

19. Vassallo M, Stockdale R, Sharma JC, Briggs R, Allen S: A comparative study of the use of four fall risk assessment tools on acute medical wards. $J$ Am Geriatr Soc 2005, 53(6):1034-1038.

20. Lamb SE, Jorstad-Stein EC, Hauer K, Becker C: Development of a common outcome data set for fall injury prevention trials: the Prevention of Falls Network Europe consensus. J Am Geriatr Soc 2005, 53(9):1618-1622.

21. Armitage PBB, Matthews JNS: Statistical Methods in Medical Research 4th edition. Oxford: Blackwell Science; 2002

22. Eagle DJ, Salama S, Whitman D, Evans LA, Ho E, Olde J: Comparison of three instruments in predicting accidental falls in selected inpatients in a general teaching hospital. J Gerontol Nurs 1999, 25(7):40-45.

23. Myers $\mathrm{H}$, Nikoletti S: Fall risk assessment: a prospective investigation of nurses' clinical judgement and risk assessment tools in predicting patient falls. Int J Nurs Pract 2003, 9(3):158-165 
24. Vassallo M, Poynter L, Sharma JC, Kwan J, Allen SC: Fall risk-assessment tools compared with clinical judgment: an evaluation in a rehabilitation ward. Age Ageing 2008, 37(3):277-281.

25. Webster J, Courtney M, Marsh N, Gale C, Abbott B, Mackenzie-Ross A, McRae P: The STRATIFY tool and clinical judgment were poor predictors of falling in an acute hospital setting. J Clin Epidemiol 2010, 63(1):109-13.

26. Parker MJ, Gillespie WJ, Gillespie LD: Effectiveness of hip protectors for preventing hip fractures in elderly people: systematic review. $B M J$ 2006, 332(7541):571-574.

27. Johal KS, Boulton C, Moran CG: Hip fractures after falls in hospital: retrospective observational cohort study. Injury 2009, 40(2):201-204.

28. Haines TPHK, Bennell KL, Osborne RH: Hip protector use amongst older hospital inpatients: compliance and functional consequences. Age Ageing 2006, 35(5):520-523.

29. Webster J, Courtney M, O'Rourke P, Marsh N, Gale C, Abbott B, McRae P, Mason K: Should elderly patients be screened for their 'falls risk'? Validity of the STRATIFY falls screening tool and predictors of falls in a large acute hospital. Age Ageing 2008, 37(6):702-706

30. Haines T, Kuys SS, Morrison G, Clarke J, Bew P: Cost-effectiveness analysis of screening for risk of in-hospital falls using physiotherapist clinical judgement. Medical care 2009, 47(4):448-456.

31. Haines TP, Hill KD, Bennell KL, Osborne RH: Recurrent events counted in evaluations of predictive accuracy. J Clin Epidemiol 2006, 59(11):1155-1161.

Pre-publication history

The pre-publication history for this paper can be accessed here: http://www.biomedcentral.com/1472-6963/10/106/prepub

doi: $10.1186 / 1472-6963-10-106$

Cite this article as: Toyabe, World Health Organization fracture risk assessment tool in the assessment of fractures after falls in hospital BMC Health Services Research 2010, 10:106

Submit your next manuscript to BioMed Centra and take full advantage of:

- Convenient online submission

- Thorough peer review

- No space constraints or color figure charges

- Immediate publication on acceptance

- Inclusion in PubMed, CAS, Scopus and Google Scholar

- Research which is freely available for redistribution

Submit your manuscript at www.biomedcentral.com/submit
C) Biomed Central 